\title{
Computation of a suburban night train timetable based on key performance indicators
}

\author{
B. Schittenhelm ${ }^{1,2} \&$ A. Landex ${ }^{1}$ \\ ${ }^{I}$ Department of Transport, Technical University of Denmark, Denmark \\ ${ }^{2}$ Traffic Planning, Rail Net Denmark, Denmark
}

\begin{abstract}
Timetable evaluation can be based on a set of key performance indicators. This article presents six essential key performance indicators: fixed interval service frequency, direct connections, transfer waiting time, use of dedicated rolling stock, dedicated train personnel, dedicated tracks and travel time. A short description and specific calculation method is given for each of these. The article recommends three different approaches for dividing the railway network into sections of analysis in regards to the key performance indicators. Three timetable variants for suburban night trains in Copenhagen are evaluated. Each timetable variant was created with a different performance focus. Values for each of the six key performance indicators are calculated and an average value is found for all timetable variants. It can be concluded that the actual implemented timetable receives the highest scores, but a clear picture of which timetable variant is best is not achieved. To get a clearer picture, the introduction of weights is recommended both for the indicators as a whole and in the specific calculation methods. A prioritization of the selected key performance indicators is essential and weights in form of, for example passenger numbers, are needed in the specific calculations.
\end{abstract}

Keywords: timetable, railway timetable, timetable evaluation, key performance indicators, sections of analyses.

\section{Introduction}

On Friday, November 20, 2009, a timetable for suburban night trains was introduced in Copenhagen, Denmark. This timetable was mainly based on input from the train operating company (TOC) DSB S-tog; this is the only TOC 
operating trains on this part of the network owned by infrastructure manager (IM) Rail Net Denmark.

The starting point for DSB S-tog was the existing contingency timetable which is used in case of large disruptions in traffic. The timetable operates with 4 service lines stopping at all stations and running with a service frequency of 20 minutes. It was decided to reuse the train service lines, arrival and departure times from this timetable - but with a frequency of 1 train per hour. In a normal daytime service, situation line structures are more complicated. Each suburban railway line is serviced with a slow stopping line servicing the inner part of the railway line and a faster line servicing the outer part. See figure 1.

This results in shorter travelling times for passengers. Each line has a service frequency of 10 minutes.

New timetable proposals should be evaluated and then either rejected, altered or implemented. To perform a fast and efficient evaluation of a given timetable a series of key performance indicators (KPI) have been developed and suggested [1]: Timetable structure, timetable complexity, travel time, transfers and punctuality and reliability. Each indicator consists of up to several quantitative indexes. These give a good first insight into a timetable's strengths and weaknesses. From this group of indexes, 6 have been chosen for the timetable evaluation in this paper.

Three suburban night train timetable variants have been proposed. In section 2 the proposed timetable variants are presented. Section 3 examines how the network should be divided into sections for analyses in regard to timetable
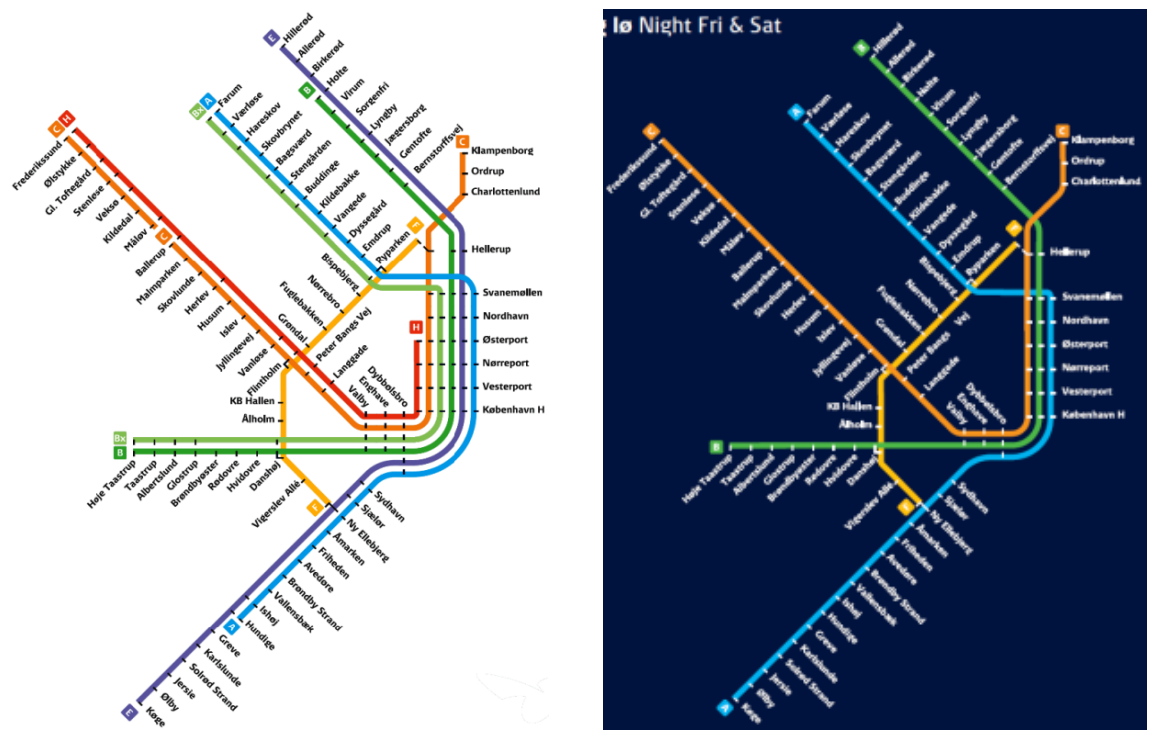

Figure 1: DSB S-tog timetables left: day (10 minute frequency per line); right: night (1 hour frequency per line). 
evaluation KPI. The KPI are described and calculated in section 4. A discussion of results and perspectives of these can be found in section 5. Finally, conclusions are drawn up in section 6.

\section{Timetable variants}

To avoid inconvenience for the many daily passengers, most of the maintenance works takes place during night time. Therefore, the main concern of Rail Net Denmark regarding timetables for running night trains on the suburban railway network was that maintenance work could continue to take place unhindered during nights. This resulted in two essential requirements:

1. Planned traffic must be able to be handled by only one track through the central part of the network

2. Running times on the outer part of the network should allow for trains to run with reduced speed on sections of the network - thereby making it possible to run traffic on one track only between 2 crossovers.

\subsection{Proposed timetable from DSB S-tog}

DSB S-tog proposed a timetable and this was implemented. It consists of 4 lines stopping at all stations. Lines $\mathrm{A}, \mathrm{B}$ and $\mathrm{C}$ have a frequency of 1 train per hour and the independent "half circle" line $\mathrm{F}$ has a 30 minute frequency. Lines A, B and $\mathrm{C}$ each need minimum 3 train sets and line F 2 train sets to carry out this timetable variant. See table 1.

This timetable does not establish a fixed service interval of 20minutes between trains on the shared line section of lines A, B and C, but creates nearly a 30minute service interval.

To improve this condition two further timetable variants have been developed. Both ensure a fixed interval service frequency of 20 minutes on the shared line section. In the first alternative, the arrival and departure times of line $\mathrm{B}$ and $\mathrm{C}$ have simply been translated.

In timetable variant 2 the philosophy of having fixed train service lines has been abandoned and a flexible approach been taken. Travel times between stations on the outer part of the network have been changed to follow timetable planning rules. This gives slightly shorter travelling times.

Table 1: $\quad$ Timetable variant DSB S-tog.

\begin{tabular}{|c|c|c|c|c|c|c|c|c|}
\hline $\begin{array}{l}\text { Arr } \\
\text { Dep }\end{array}$ & $\downarrow \quad$ Line $\mathbf{A} \uparrow$ & $\begin{array}{l}\text { Arr } \\
\text { Dep }\end{array}$ & $\begin{array}{l}\text { Arr } \\
\text { Dep }\end{array}$ & $\downarrow \quad$ Line B $\uparrow$ & $\begin{array}{l}\text { Arr } \\
\text { Dep }\end{array}$ & $\begin{array}{l}\text { Arr } \\
\text { Dep }\end{array}$ & $\downarrow$ Line $\mathrm{C} \uparrow$ & $\begin{array}{l}\text { Arr } \\
\text { Dep }\end{array}$ \\
\hline $46 \frac{1}{2}$ & Køge & $39^{1 / 2}$ & 31 & Høje Taastrup & $15^{1 / 2}$ & 38 & Frederikssund & $08^{1 / 2}$ \\
\hline $\begin{array}{l}32 \\
33\end{array}$ & København H & $\begin{array}{l}54 \\
53 \\
\end{array}$ & $\begin{array}{l}56 \\
57 \\
\end{array}$ & København H & $\begin{array}{l}50 \\
49 \\
\end{array}$ & $\begin{array}{l}28 \\
29\end{array}$ & København H & $\begin{array}{l}18 \\
17\end{array}$ \\
\hline 09 & Farum & 16 & $441 / 2$ & Hillerød & 02 & 49 & Klampenborg & 56 \\
\hline \multicolumn{3}{|c|}{3 trains needed } & \multicolumn{3}{|c|}{3 trains needed } & \multicolumn{3}{|c|}{3 trains needed } \\
\hline
\end{tabular}




\subsection{Alternative timetable variant 1}

Timetable variant 1 focuses on regular intervals between trains through Copenhagen. See table 2. Trains from the south arrive in minute 1232 and 52 and from the north in 133353 at Copenhagen central station (København $\mathrm{H}$ in Danish). Trains in the two driving directions pass each other here to ensure that traffic can be handled using only one track between København $\mathrm{H}$ and the next set of crossovers at Østerport station. The travel time between København H and Østerport is 6 minutes - this allows for reduced speed for trains travelling in the secondary driving direction in case of single track operation. It takes 11 trains to run timetable variant 1 .

In timetable variant 1 , the arrival and departure times for line A are the same as in the timetable proposed by DSB S-tog. Times had to be changed for line B and $C$ to achieve fixed interval frequency of 20 minutes. The possible positive effect of recognizable and easy to remember arrival and departure times in the DSB S-tog timetable cannot be complete since customers still must find out/remember which one of the 3 possible departure times is relevant for them.

Timetable variant 1 maintains line $\mathrm{F}$ as proposed by DSB S-tog in the timetable for night trains. Line F requires 2 trains to be operated. Therefore 11 trains are needed to operate timetable variant 1.

\subsection{Alternative timetable variant 2}

Disregarding fixed line structures in timetables, a second variant has been developed. See table 3 .

A train follows the line structure indicated with numbers 1 to 4 in figure 2 . Trains between Høje Taastrup and Klampenborg are fixed to this line.

Timetable variant 2 maintains line $F$ as it is planned in the DSB S-tog timetable for night trains. Line $\mathrm{F}$ requires 2 trains to be run. All 3 investigated timetable variants need 11 trains to be implemented.

\section{Railway sections of analysis}

In the following section a series of KPI are calculated for the 3 presented timetable variants. Since characteristics of timetable variants depend on which part of the network is being investigated, it is important to divide the network in reasonable sections of analysis. How to choose these sections is highly dependent on the specific KPI and how it is calculated.

Table 2: $\quad$ Timetable variant 1 .

\begin{tabular}{|c|c|c|c|c|c|c|c|c|}
\hline $\begin{array}{l}\text { Arr } \\
\text { Dep }\end{array}$ & $\downarrow$ Line $\mathbf{A} \uparrow$ & $\begin{array}{l}\text { Arr } \\
\text { Dep }\end{array}$ & $\begin{array}{l}\text { Arr } \\
\text { Dep }\end{array}$ & $\downarrow \quad$ Line B $\uparrow$ & $\begin{array}{l}\text { Arr } \\
\text { Dep }\end{array}$ & $\begin{array}{l}\text { Arr } \\
\text { Dep }\end{array}$ & $\downarrow$ Line $\mathrm{C} \uparrow$ & $\begin{array}{l}\text { Arr } \\
\text { Dep }\end{array}$ \\
\hline $461 / 2$ & Køge & $39^{1 / 2}$ & 27 & Нøje Taastrup & 59 & 22 & Frederikssund & 04 \\
\hline $\begin{array}{l}32 \\
33\end{array}$ & København H & $\begin{array}{l}54 \\
53\end{array}$ & $\begin{array}{l}52 \\
53\end{array}$ & København H & $\begin{array}{l}34 \\
33\end{array}$ & $\begin{array}{l}12 \\
13\end{array}$ & København H & $\begin{array}{l}14 \\
13\end{array}$ \\
\hline 09 & Farum & 17 & $40^{1 / 2}$ & Hillerød & $45^{1 / 2}$ & 33 & Klampenborg & 53 \\
\hline \multicolumn{3}{|c|}{3 trains needed } & \multicolumn{3}{|c|}{3 trains needed } & \multicolumn{3}{|c|}{3 trains needed } \\
\hline
\end{tabular}


Table 3: $\quad$ Timetable variant 2.

\begin{tabular}{|c|c|c|c|}
\hline From & To & Departure & Arrival \\
\hline København $\mathrm{H}$ & Høje Taastrup & 26 & 50 \\
\hline Høje Taastrup & København $\mathrm{H}$ & 01 & 25 \\
\hline København $\mathrm{H}$ & Klampenborg & 26 & $45 \frac{1}{2}$ \\
\hline Klampenborg & København $\mathrm{H}$ & $05 \frac{1}{2}$ & 25 \\
\hline København H & Køge & 06 & 48 \\
\hline Køge & København $\mathrm{H}$ & 23 & 05 \\
\hline København H & Hillerød & 06 & 51 \\
\hline Hillerød & København & 00 & 45 \\
\hline København $\mathrm{H}$ & Frederikssund & 46 & $34 \frac{1}{2}$ \\
\hline Frederikssund & København H & $566^{1 / 2}$ & 45 \\
\hline København $\mathrm{H}$ & Farum & 46 & 22 \\
\hline Farum & København $\mathrm{H}$ & 29 & 05 \\
\hline
\end{tabular}

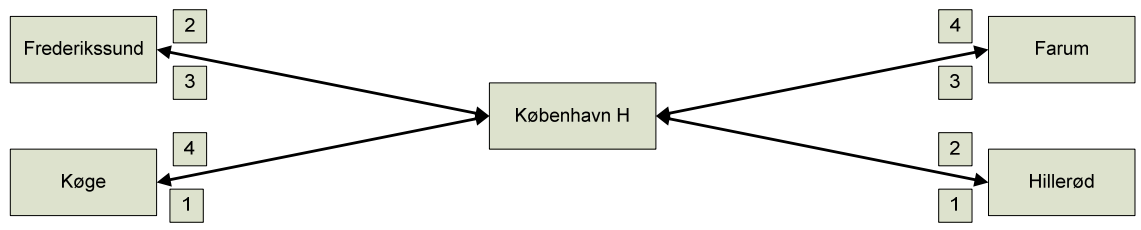

Figure 2: $\quad$ Flexible line structure in timetable variant 2.

When calculating KPI, for example service frequency and travelling time, inspiration can be taken from the UIC capacity consumption calculation method [2]. Following the Danish adaption of the recommendations the network is divided into analysis sections at line end stations/terminus and junctions [3]:

- Køge (terminus) - Dybølsbro (junction)

- Høje Taastrup (terminus) - Valby (junction)

- Frederikssund (terminus) - Valby (junction)

- Valby (junction) - Dybølsbro (junction)

- Dybølsbro (junction) - Svanemøllen (junction)

- Svanemøllen (junction) - Farum (terminus)

- Svanemøllen (junction) - Hellerup (junction)

- Hellerup (junction) - Hillerød (terminus)

- Hellerup (junction) - Klampenborg (terminus)

- Hellerup (terminus) - Ny Ellebjerg (terminus)

Between these sections the number of trains per hour change and thereby potentially also service frequencies. This can have influence on the running time as a higher number of trains can cause a higher level of scheduled waiting time in the timetable. When passing a junction a Train service line can go from having dedicated tracks to shared tracks with other lines. 
Transfers take place at stations. Only stations with transfer possibilities are of interest when calculating KPI for transfers. These stations are: Ny Ellebjerg, Danshøj, Flintholm, Ryparken, Hellerup, Svanemøllen, Dybølsbro and Valby.

Looking at KPI for dedicated rolling stock or crew for a train service, a detailed approach in regards to analysis sections makes no sense. A more overall look on the network is needed. A ratio of departures or train runs becomes more important.

\section{Computation of timetable key performance indicators}

In the following six sections a selected series of KPI will be shortly described and their method of calculation shown. These KPI reveal the main differences between the 3 suggested timetable variants.

\subsection{Fixed interval frequency}

The used clock faced index in England [4] is not able to evaluate the regularity of service frequency of trains in a given analysis section. Therefore, the following index for regularity in frequency is proposed. See equation (1).

$$
I_{\text {regular frequency }}=\frac{H_{12}}{H_{a v}} \times \frac{H_{23}}{H_{a v}} \times \ldots \times \frac{H_{n m}}{H_{a v}}
$$

$\mathrm{I}_{\text {regular frequency }}=$ Index for regularity of frequency

$\mathrm{H}_{\mathrm{nm}}=$ Timetable headway time between trains $\mathrm{n}$ and $\mathrm{m}$ $\mathrm{H}_{\mathrm{av}}=$ Average headway time if regular frequency

A perfect regular frequency will give an index value equal to 1 . A highly irregular frequency will give a value close to 0 . From a customer point of view, a regular frequency is in general preferable to an irregular [4].

\subsection{Transfers}

There are 84 stations on the suburban network. In the timetable proposed by DSB S-tog train service line A has 35 stations, line B has 28 (7 are shared with other lines), line $\mathrm{C}$ has 31 (10 are shared with other lines) and line F has 12 stations ( 5 are shared with other lines). The layout of the network in combination with service line structure ensures that from a given starting station you can reach any other station with maximum one transfer. It may though be faster for passengers to choose a route with two transfers instead of one - e.g. from Farum to Høje Taastrup with transfers at Ryparken and Danshøj.

Transfers are mostly avoided by passengers - if possible. An index for direct connections can be calculated as shown in equation (2).

$$
I_{\text {Direct connections }}=\frac{\sum \text { connections without transfer }}{\sum \text { connections }}
$$


This index is calculated for each station and then summed up to get a timetable dependent index. For example, a station only served by line A: 34 stations can be reached without transfer out of 83. This gives an $\mathrm{I}_{\text {Direct connections }}=$ $34 / 83=0.41$. There are 26 of these stations. For København H you have: 76 stations can be reached without transfer out of 83 . $\mathrm{I}_{\text {Direct connections }}=76 / 83=0.92$. There are 7 stations with this characteristic.

To measure the quality of transfers, one key parameter is prolongation of the travel time caused by transfers. An index for this is suggested in equation (3). If travel time is not prolonged an index value of 1 is achieved. The index goes down towards 0 with increasing waiting time for transfers.

$$
I_{\text {transfer waiting time }}=\frac{\sum \text { Minimum waiting time }}{\sum \text { Waiting time with transfer }}
$$

Figure 3 gives an overview of transfer stations in the network and the arrival and departure times from the DSB S-tog timetable variant. It is impossible to exchange making a transfer with a direct train at Ny Ellebjerg, Danshøj, Flintholm and Ryparken stations. Minimum transfer time is set to 4 minutes at these stations. For other stations the following rule is used: If a transfer can be made at the same platform, minimum transfer time is set to 2 minutes, if not 4 minutes.

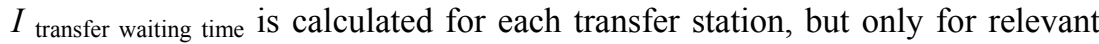
transfers. The station indexes are then summed up and averaged to get an overall index for the given timetable variant. For example, at Ny Ellebjerg there are 6 transfer possibilities: Each arrival from line F (00 and 30) can transfer to line A

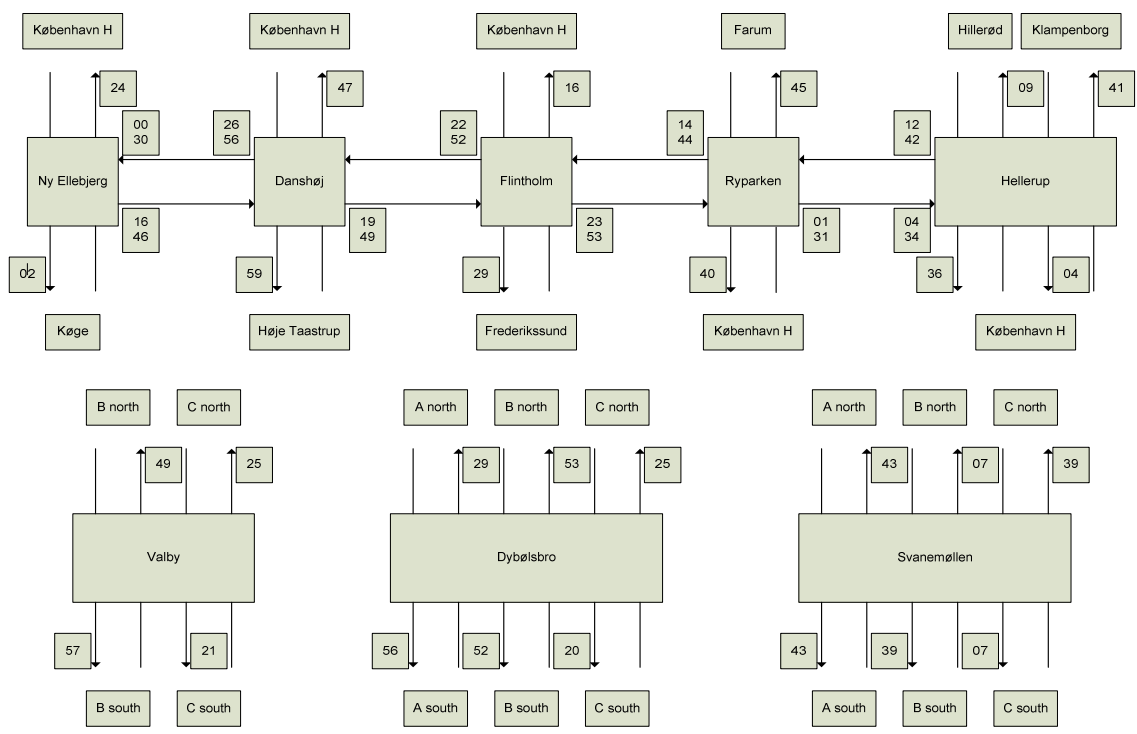

Figure 3: Overview of selected transfer stations and times. 
(02 and 24). The arrivals from line A (02 and 24) will chose the next departure on line F (16 and 46). Transfer times are: $(24+2+32+54+14+22) \mathrm{min} /(6 \times 4) \mathrm{min}$ $=0.17$.

\subsection{Dedicated rolling stock}

The risk of consecutive delays is reduced if the same rolling stock is used on one line of service only - line dedicated rolling stock. This is because a cancellation of a train or a break down on one line not necessarily will spread to other lines. The proposed KPI to evaluate use of dedicated rolling stock looks at the rate between sums of all train runs and runs with dedicated rolling stock. See equation (4) $[3,5]$.

$$
I_{\text {dedicated rolling stock }}=\frac{\sum \text { Train departures with dedicated rolling stock }}{\sum \text { Train departures }}
$$

If all rolling stock is dedicated to one train service line, the index value will be 1 . The opposite situation gives a value equal to 0 .

\subsection{Dedicated train personnel}

As with rolling stock, train personnel can be dedicated to one train service line. This reduces the risk of consecutive delays because delayed train personnel from one service line can bring the delay with them to other potentially unaffected service lines - e.g. a train driver arriving delayed will not result in another train not being able to move $[1,5]$. Below the developed KPI looks at the ratio between sums of all train runs and runs with shared train personnel.

$$
I_{\text {dedicated train personnel }}=\frac{\sum \text { Train departures with dedicated train personnel }}{\sum \text { Train departures }}
$$

Using only dedicated personnel gives an index value of 1 . The opposite gives an index equal to 0 .

This KPI has the same value for all 3 timetable variants. Rules for train personnel rostering are based on agreements between TOC and railway unions. All suburban trains change train personnel at København H. Train drivers start/ end their shift or change to other service lines when passing this station. Train drivers for line $\mathrm{F}$ have to travel between København $\mathrm{H}$ and Hellerup.

\subsection{Dedicated tracks}

Only one infrastructure variant is available to the TOC and it is used in the same manner by all 3 timetable variants. Service lines have dedicated tracks on the outer part of the network and have to share tracks on the central part. A KPI for dedicated tracks is suggested in equation (6). 


$$
I_{\text {dedicated tracks }}=\frac{\sum \text { Analysis sections with dedicated tracks }}{\sum \text { Analysis sections }}
$$

For the examined timetable variants, 7 out of 10 analysis sections have dedicated tracks to train services. This giving an $\mathrm{I}_{\text {Dedicated tracks }}=7 / 10=0.70$.

\subsection{Travel time}

Passenger want as short travel times as possible - still arriving on time - while the TOC and IM want a robust and timetable where it is possible to absorb smaller delays. Therefore, running time supplements are included in a timetable. A KPI that describes the ratio between planned travel time in a given timetable and minimum travel time according to planning rules is suggested. This is calculated for each analysis section and each train service line. See equation 7.

$$
I_{\text {Travel time }}=\frac{\text { Travel time }_{\text {Analysis section, minimum }}}{\text { Travel time }_{\text {Analysis section, timetable }}}
$$

A train from Køge to Dybølsbro uses 42 minutes and 50 seconds according to timetable variant 1 , while the minimum travel time is 40 minutes and 5 seconds. This gives an $\mathrm{I}_{\text {Travel time }}=0.94$.

\subsection{Calculated KPI}

Table 4 gives an overview of the calculated KPI for the 3 investigated timetable variants.

\section{Discussion and perspective}

Three different approaches were necessary to define sections for analyses for timetable evaluation that can be applied to all used KPI. For KPI travel time, dedicated tracks and fixed interval frequency a similar division of the network as suggested in the UIC-406 method is used [2, 3]. KPI for transfers are calculated on station level. A ratio of departures is used for calculating KPI for dedicated trains and personnel. Using different analysis sections has not weakened the KPI approach for timetable evaluation and comparison.

Looking at the average KPI score achieved by the 3 timetable variants, it becomes evident that weighting of the KPI is needed. The importance of each KPI needs to be defined and weights based on this created. These weights of importance can, for example, be found by holding a decision conference where all timetable stakeholders take part and come to an agreement. This will be very difficult but is an important input for timetable evaluation.

Weights should also be applied within the calculation methods for the KPI for example, a transfer waiting time should be multiplied with the number of passengers making the given transfer. In this way more unambiguous evaluation results of timetable variants can be produced and create a better basis for 
Table 4: $\quad$ Calculated KPI for timetables variants.

\begin{tabular}{|c|c|c|c|c|}
\hline KPI & Analysis section / station & $\begin{array}{c}\text { Timetable DSB } \\
\text { S-tog }\end{array}$ & Timetable 1 & Timetable 2 \\
\hline \multirow{9}{*}{$\begin{array}{l}\text { Regularity } \\
\text { of service } \\
\text { frequency }\end{array}$} & Køge - Dybølsbro & 1.00 & 1.00 & 1.00 \\
\hline & Høje Taastrup - Valby & 1.00 & 1.00 & 1.00 \\
\hline & Frederikssund - Valby & 1.00 & 1.00 & 1.00 \\
\hline & Valby - Dybølsbro & 0.99 & 0.89 & 0.89 \\
\hline & Dybølsbro - Svanemøllen & 0.38 & 1.00 & 1.00 \\
\hline & Svanemøllen - Farum & 1.00 & 1.00 & 1.00 \\
\hline & Svanemøllen - Hellerup & 0.99 & 0.89 & 0.89 \\
\hline & Hellerup - Hillerød & 1.00 & 1.00 & 1.00 \\
\hline & Hellerup - Klampenborg & 1.00 & 1.00 & 1.00 \\
\hline \multirow{9}{*}{ Transfers } & $\mathrm{I}_{\text {Direct connections }}$ Timetable & 0.58 & 0.58 & 0.56 \\
\hline & $\mathrm{I}_{\text {transfer wating time }} \mathrm{Ny}$ Ellebjerg & 0.16 & 0.16 & 0.15 \\
\hline & $\mathrm{I}_{\text {transfer waiting time }}$ Danshøj & 0.16 & 0.15 & 0.15 \\
\hline & $\mathrm{I}_{\text {transfer waiting time }}$ Flintholm & 0.16 & 0.18 & 0.18 \\
\hline & $\mathrm{I}_{\text {transfer waiting time }}$ Ryparken & 0.20 & 0.17 & 0.15 \\
\hline & $\mathrm{I}_{\text {transfer waiting time }}$ Hellerup & 0.14 & 0.13 & 0.13 \\
\hline & I transfer waiting time Svanemøllen & 0.08 & 0.09 & 0.08 \\
\hline & $\mathrm{I}_{\text {transfer waiting time }}$ Dybølsbro & 0.09 & 0.09 & 0.08 \\
\hline & $\mathrm{I}_{\text {transfer waiting time }}$ Valby & 0.06 & 0.08 & 0.08 \\
\hline $\begin{array}{l}\text { Dedicated } \\
\text { rolling stock }\end{array}$ & $\mathrm{I}_{\text {Dedicated rolling stock }}$ timetable & 1.00 & 1.00 & 0.33 \\
\hline $\begin{array}{l}\text { Dedicated } \\
\text { personnel }\end{array}$ & $\mathrm{I}_{\text {Dedicated personnel }}$ timetable & 0.00 & 0.00 & 0.00 \\
\hline $\begin{array}{l}\text { Dedicated } \\
\text { tracks }\end{array}$ & $\mathrm{I}_{\text {Dedicated tracks }}$ timetable & 0.70 & 0.70 & 0.70 \\
\hline \multirow{9}{*}{ Travel time } & Køge - Dybølsbro & 0.94 & 0.94 & 1.00 \\
\hline & Høje Taastrup - Valby & 0.98 & 0.98 & 1.00 \\
\hline & Frederikssund - Valby & 0.98 & 0.98 & 1.00 \\
\hline & Valby - Dybølsbro & 1.04 & 1.04 & 1.00 \\
\hline & Dybølsbro - Svanemøllen & 0.92 & 0.92 & 0.92 \\
\hline & Svanemøllen - Farum & 0.97 & 0.97 & 1.00 \\
\hline & Svanemøllen - Hellerup & 0.95 & 0.95 & 1.00 \\
\hline & Hellerup - Hillerød & 0.95 & 0.95 & 1.00 \\
\hline & Hellerup - Klampenborg & 0.97 & 0.97 & 1.00 \\
\hline \multicolumn{2}{|c|}{ Average KPI value } & 0.71 & 0.69 & 0.68 \\
\hline
\end{tabular}

deciding which timetable variant to implement. Passenger numbers were not available before the timetable was implemented since there had not been run night trains before.

The importance of a fixed interval frequency KPI depends on what timetable philosophy is preferred: Specific demand oriented - or fixed interval? Passenger demands for a night train timetable probably focus on transporting people between suburbs and the city centre. Since the service frequency is only 1 train per hour for each train service line -3 trains per hour through Copenhagen - this KPI loses some importance.

This gives the possibility to look into a different timetable category where all trains meet at København H, for example on the hour - inspired by the Swiss Bahn 2000 timetable concept. This requires that 2 different trains can make use 
of the same plat form track at the same time, which technically is possible. Reduced functionality in the existing signalling system reduces the headway between two trains running in the secondary direction on a given track to approximate 5 minutes. The essential requirements from Rail Net Denmark - the possibility to unhindered carrying out maintenance work at night - make this timetable category unfeasible. This timetable category could be looked into when an improved signalling system - for example a CBTC system - is available.

The KPI for transfer waiting time identifies good and bad transfer possibilities at stations but does not indicate how many customers are affected by these. Weighting each transfer relation with the number of passengers making use of it - looking at passenger transfer minutes instead of simply transfer minutes - would give a more correct picture.

Transfer stations have been chosen based on an unbiased approach to the train service line patterns. If the same transfer can be achieved at a series of stations, it has not been investigated if one station offers a more comfortable transfer than the others e.g. because of a station canopy, and therefore would be chosen by transferring passengers.

One transfer aspect has not been covered by the chosen transfer KPI: In the DSB S-tog timetable variant it is possible to make a transfer from the train leaving Svanemøllen towards København $\mathrm{H}$ at minute 43 to the train leaving Svanemøllen towards København $\mathrm{H}$ at minute 39, by using the $\mathrm{F}$ line from Ryparken to Ny Ellebjerg. Unfortunately this is not possible for passengers in the opposite travelling direction between trains leaving Dybølsbro at minute 25 and 29. The DSB S-tog timetable variant gives better opportunities to make use of line $\mathrm{F}$ in regards to transfer possibilities but is not given any reward for this. To deal with this, developing an existing KPI or adding an additional KPI is needed.

Travel time is a very important KPI. The suggested KPI indicates if planned travelling times, within a given analysis section, are close to the shortest possible. This should be weighted with the number of passengers affected by this to see how many passenger scheduled waiting time minutes are generated.

A new timetable can attract new passengers to an existing railway system. To calculate weighted KPI for a number of new timetable variants, input from a traffic model estimating future passenger numbers is needed. Having this available improves the evaluation of future timetables.

To get an insight into the influence of dedicated rolling stock, personnel and tracks to a timetable variant's vulnerability to primary delays and delay transfers from train to train, a simulation of the timetable can be helpful. The punctuality data from a simulation can be multiplied with passenger numbers using a passenger delay model, giving an estimate of passenger delay minutes $[1,5]$.

In this timetable variant evaluation and comparison, changes only occur on parts of the network served by train service lines A, B and C. The timetable for Line $\mathrm{F}$ is kept constant in all 3 variants. Creating a fixed service frequency of 20 minutes on parts of the network could give the idea to do the same on line F. This can potentially improve the transfer KPI for stations on line F but increases the need for trains from 2 to 3 . The arrival and departure times for line F could also simply be translated to potentially achieve better transfer waiting times. 


\section{Conclusion}

Six key performance indicators (KPI) have been selected for use in an evaluation of 3 timetable variants for suburban night trains in Copenhagen. These KPIs are: fixed interval frequency, transfers, dedicated rolling stock, dedicated personnel, dedicated tracks and travel time.

Calculation of these KPI demanded three different ways to divide the railway network into sections of analyses. An approach as suggested in the UIC-406 method has been adapted, relevant transfer stations identified and ratios of train departures been recommended.

Evaluation of different alternatives for suburban night trains using selected KPI scores show that the implemented DSB S-tog suburban night train timetable variant is the best. It achieved a KPI score of 0.71 whereas timetable variants 1 and 2 got 0.69 and 0.68 respectively. This indicates that DSB S-tog has taken the topics covered by the proposed KPI into account in their timetable development process.

The differences in achieved scores are minimal and therefore give a weak basis for making a decision on which timetable variant to implement. To see the differences between timetables more clearly it is necessary that each KPI must be weighted with its importance and weights - for example estimated or registered passenger numbers - also have to be part of the specific calculations for each KPI.

\section{References}

[1] Schittenhelm, B. \& Landex, A., Quantitative Methods to Evaluate Timetable Attractiveness, Proc. of the $3^{\text {rd }}$ Int. Seminar on Railway Operations Modelling and Analysis, Zürich, 2009

[2] UIC 406 leaflet 406, Capacity, $1^{\text {st }}$ edition, UIC International Union of Railways, France, 2004

[3] Landex, A., Methods to estimate railway capacity and passenger delays, PhD Thesis, Technical University of Denmark, 2008

[4] Wardman, M. \& Shires, J. \& Lythgoe, W. \& Tyler, J., Consumer benefits and demand impacts of regular train timetables, International Journal of Transport Management, (2), 2004

[5] Landex, A. \& Nielsen, O.A., Modelling expected train passenger delays on large scale railway networks, Proc. of the $7^{\text {th }}$ World Congress on Railway Research, 2006

[6] Landex, A. \& Nielsen O.A., Timetable Planning \& Information Quality, WIT Press, (chapter) Simulation of disturbances and modelling of expected train passenger delays, eds. I.A. Hansen pp. 85-94, 2010 